\title{
On the effect of digital elevation model accuracy on hydrology and geomorphology
}

\author{
Jeffrey P. Walker and Garry R. Willgoose \\ Department of Civil, Surveying and Environmental Engineering, University of Newcastle \\ Callaghan, New South Wales, Australia
}

\begin{abstract}
This study compares published cartometric and photogrammetric digital elevation models (DEMs) of various grid spacings with a ground truth data set, obtained by ground survey, and studies the implications of these differences on key hydrologic statistics. Inferred catchment sizes and stream networks from published DEMs were found to be significantly different than those from the ground truth in most instances. Furthermore, the width functions and cumulative area relationships determined from the published DEMs were found to fall consistently outside the $90 \%$ confidence limits determined from the ground truth for more than $60 \%$ of the relationship, suggesting that these hydrologic properties are poorly estimated from published DEMs. However, the slope-area relationships determined from published DEMs were found to be less sensitive to catchment shape, size, and stream network, with the relationship falling outside the $90 \%$ confidence limits for less than $40 \%$ of the relationship for all catchments identified from the published DEMs. A published relationship linking the horizontal resolution with the vertical accuracy of the DEM was tested, predicting a horizontal resolution of about $10 \mathrm{~m}$ for the published DEMs tested.
\end{abstract}

\section{Introduction}

Recent developments in computational models to monitor and predict hydrology, erosion, and landscape evolution by Earth and water scientists rely heavily on the integrity of the digital elevation models (DEMs) available [Moore and Grayson, 1991; Moore et al., 1991; Lane et al., 1994]. Fryer et al. [1994] suggested that Earth and water scientists are not fully aware of the limitations of DEMs as sources of spatial information. This concern is not unwarranted, with few published reports on the accuracy of DEM-derived elevation and slope [Bolstad and Stowe, 1994; Robinson, 1994] or the effects introduced on geomorphic parameters; DEMs are created, distributed, and used very frequently without any reference to the magnitude of the error implied or to the methods applied to its disclosure or correction [Felicísimo, 1994].

A DEM consists of either (1) a two-dimensional array of numbers that represents the spatial distribution of elevations on a regular grid; (2) a set of $x, y$, and $z$ coordinates for an irregular network of points; or (3) contour strings stored in the form of $x, y$ coordinate pairs along each contour line of specified elevation. DEMs on a regular grid are the most widely used data structures because of their computational efficiency and lower storage requirements. Furthermore, grid DEMs are used to calculate all other types of digital terrain models whose accuracy is limited by that of the original source data [Florinsky, 1998]. However, Moore et al. [1991] notes that grid DEMs have several disadvantages: (1) they cannot easily handle discontinuities in elevation; (2) the resolution of the mesh effects the results and computational efficiency; (3) grid spacing needs to be based on the roughest terrain in the catchment, resulting in redundancy in smoother areas; and (4) the computed flow Copyright 1999 by the American Geophysical Union.

Paper number 1999WR900034.

0043-1397/99/1999WR900034\$09.00 paths tend to zigzag, not following the drainage lines, and are hence systematically too long.

Generally, raw elevation data in the form of stereophotographs or field surveys and the equipment necessary to process these data are not readily available to potential users of a DEM. Most users are therefore forced to rely on the DEMs published by government agencies. The most common form of DEM available in Australia, Organisation Européenne d'Estudes Photogrammetriques Experimentales member countries, and the United States are those produced by digitizing the contours on existing topographical maps [Moore et al., 1991; Robinson, 1994], known as "cartometric DEMs." In many countries these contour-based DEMs are interpolated onto a grid. In addition to interpolation errors this process introduces artifacts such as pits or depressions, which interfere with drainage algorithms based on flow in the steepest downslope direction. In the state of New South Wales (NSW), Australia, this pit removal incorporates a drainage enforcement algorithm developed by Hutchinson [1989], which utilizes the blue lines drawn on topographic maps to represent the permanently flowing or major intermittent streams [Moore et al., 1991].

In recent years, there has been an increasing move toward using automated digital correlation techniques to generate what are known as "photogrammetric DEMs" directly from stereoscopic imagery, especially where contour data are not available or are not accurate enough [Robinson, 1994]. These methods create gridded DEMs directly with similar artifacts to the cartometric DEMs, though studies of these errors for hydrologic purposes have not been performed. An additional drawback is that the points which are correlated (used to determine the elevations) are often the tops of trees, buildings, etc., consequently requiring a significant amount of editing by hand to produce a realistic DEM [G. Burgess, personal communication, 1995].

Few studies have been undertaken on the effects of relative 


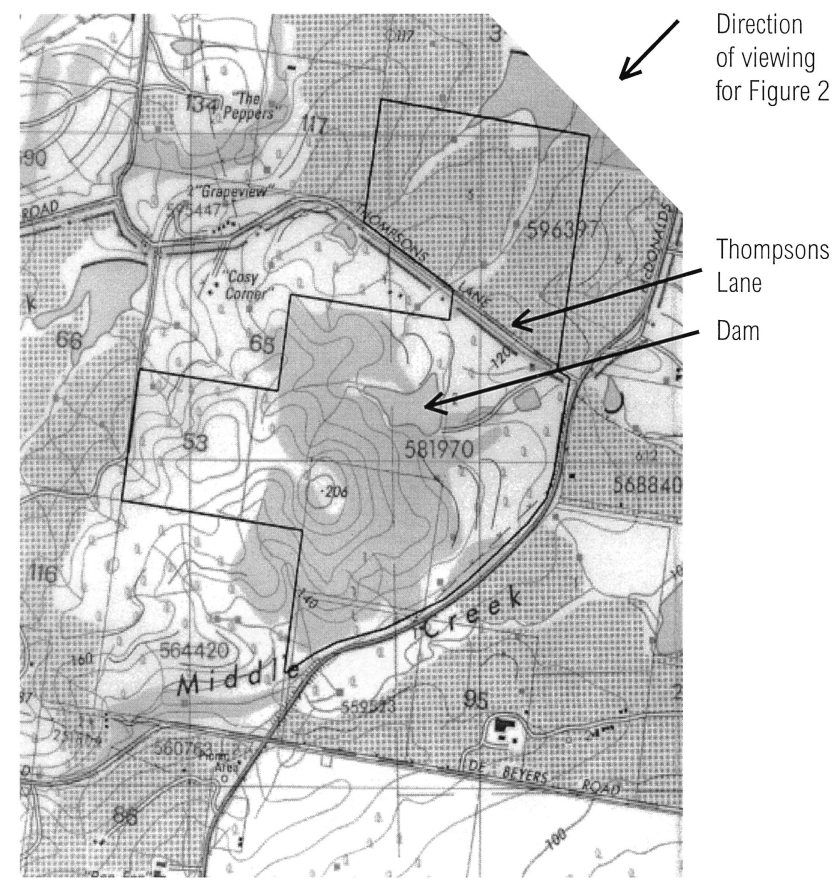

Figure 1. Extract of 1:25,000 scale series topographic map showing the location of the site under investigation (not to scale).

elevation accuracy in published DEMs on hydrologic modeling or geomorphic parameters used in hydrology. Zhang and Montgomery [1994] and Wolock and Price [1994] have investigated the effect of grid size on the topographic index used by TOPMODEL [Beven and Kirkby, 1979]. Zhang and Montgomery [1994] found that increasing the grid size resulted in an increased mean topographic index because of increased contributing area and decreased slopes, while Wolock and Price [1994] found that increasing grid size resulted in higher minimum, mean, variance, and skewness of the topographic index distribution. Wolock and Price [1994] also found that the map scale used to produce the cartometric DEM has an observable but much smaller effect on the spatial distribution of topographic index than grid spacing. Zhang and Montgomery [1994] conclude that a $10 \mathrm{~m}$ grid size presents a rational compromise between increasing resolution and data volume for simulating geomorphic and hydrologic processes. Gyasi-Agyei et al. [1995] have investigated the effect of vertical resolution of elevation data on geomorphic parameters by modifying the vertical resolution between centimeters and meters. They proposed that the vertical resolution for the DEM of a catchment should be satisfactory for extraction of the drainage network if the ratio of average elevation change per pixel (pixel drop) to elevation error is greater than unity. Once the ratio fell below unity, they were unable to reliably extract the stream network. They also found that the cumulative distributions of slope-area relationship and normalized width function were not very sensitive to the vertical resolution. It should be noted, however, that this analysis was coarse in so much as the vertical resolution was altered by factors of 10 .

To perform a comprehensive study of elevation errors on hydrology would require multiple simulations with a wide range of rainfall intensities and durations [e.g., Zhang and Montgomery, 1994], and it would be difficult to draw any gen- eral conclusions. Thus this paper takes a different tack. Hemantha and Willgoose [1996] and H. J. Perera and G. R. Willgoose (A simple model of subsurface saturation excess runoff generation based on geomorphology, 1, steady state, submitted to Water Resources Research, 1998) showed that the proportion of saturation area in a catchment dominated by saturation excess, and therefore the rate of runoff generation, can be formulated in terms of the wetness index [Beven and Kirkby, 1979], the cumulative area diagram [Tarboton et al., 1989], and the slope-area diagram [Willgoose et al., 1991]. Moreover, Surkan [1969] showed the unit hydrograph and the runoff routing response can be directly related to the catchment width function. Accordingly, we have investigated the effect of elevation errors on the following geomorphic relationships: (1) catchment boundary and stream network; (2) slope-area relationship; (3) cumulative area relationship; and (4) normalized width function.

The slope-area relationship is a log-log plot of the slope for a drainage link against the total catchment area upstream of that link [Willgoose et al., 1991], while the cumulative area relationship is a log-log plot of the percentage of pixels in the catchment having an upstream catchment area which is greater than a specified value [Tarboton et al., 1989]. The normalized width function is a frequency histogram for the number of drainage links that exist at a given distance from the catchment outlet, scaled such that the distance from the outlet ranges from zero to one and the area under the curve is one [Surkan, 1969].

A normalized width function is used to allow comparisons between catchments of different sizes and shapes to determine if generalizations can be made regarding all catchments. In addition, with the area under the width function scaled to one, it may be considered as a probability distribution function, where it describes the probability of the stream network having an "equivalent width" at a given distance from the outlet. The width function is also related to the unit hydrograph used in hydrology, as the distance axis may be transformed to time by the assumption of constant velocity.

\section{Data and Methodology}

\subsection{Data Sources}

For an assessment to be made on the accuracy of a published DEM, it is necessary to have a set of "ground truth" with a higher degree of accuracy than that of the data being investigated. The ground truth used in this research was a parcel of land of approximately $1.4 \mathrm{~km}^{2}$, situated at Pokolbin, NSW, Australia, in undulating terrain (Figure 1). Prominent features of the study site include a large farm dam, covering of trees on the southern side of Thompsons Lane (mainly on the sections with higher elevation), and vineyards on the northern side of Thompsons Lane. The catchment elevation ranges from $110 \mathrm{~m}$ Australian height datum (AHD) to $205 \mathrm{~m} \mathrm{AHD,} \mathrm{with} \mathrm{steeper}$ slopes in the southern portion of the site, flattening out to gently sloping in the northern portion of the site.

The ground survey data for this site were obtained by electronic distance measurement (EDM) tacheometry with coordinate evaluation on the Australian map grid (AMG). Data were collected at all changes of grade, as well as at any other points of interest. Therefore linear interpolation between data points to a fine-grid spacing could be performed with a high degree of accuracy. Approximately 3000 data points were collected with an average spacing of $17.7 \mathrm{~m}$. 
The published DEM data were provided by the Land Information Centre (LIC) at Bathurst, NSW, Australia. These data were provided on the AMG coordinate system thus dispensing with any georeferencing problems in making data comparisons. The published DEM data included the following.

Cartometric DEMs are the $6.25 \mathrm{~m}, 12.5 \mathrm{~m}$, and $25.0 \mathrm{~m}$ gridded elevation data from contours on the 1:25,000 scale topographical map series (10 m contour interval). Hutchinson drainage enforcement was used, and an auxiliary contour height was assigned to the shorelines of the large dams in the area. Use was also made of spot heights shown on the contour maps. In addition, $95 \mathrm{~m}$ and $105 \mathrm{~m}$ intermediate contours were added by the LIC to help with interpolation in the flatter region located in the southeast corner of the site.

Photogrammetric DEMs are $6.25 \mathrm{~m}$ and $12.5 \mathrm{~m}$ gridded elevation data produced by automatic image correlation of stereopairs of controlled photography using the Orthomax software which is a subset of the ERDAS Imagine software package (J. Perry, personal communication, 1995). No editing of the data set had been performed; hence in timbered areas, correlated points may be at treetop level or ground level.

Each of the above DEMs was produced independently from the same source data using the same parameter settings so that even at common points the elevations could be different.

The three data sources used in this study are shown as perspective surface plots in Figure 2. The plot for the ground truth DEM in Figure 2a shows a relatively smooth surface, with a few fine features clearly visible. These features are the cutting for Thompsons Lane, the large farm dam at the base of one of the gullies, as well as isolated areas with abrupt changes in elevation (see also Figure 1).

The cartometric DEM in Figure 2b shows a much smoother surface than the ground truth, with the dam being the only fine feature visible from those mentioned above. The gullies are still clearly visible, and the overall shape of the site is maintained. However, the ridge near the dam appears to have a dip in it which would allow for the catchment to drain across into the next gully. This is not the case in the ground truth.

The photogrammetric DEM in Figure 2c, however, shows an extremely rough surface with a significant amount of highfrequency noise. This plot fails to allow identification of any of the fine detail clearly visible in the previous two DEMs, and even the gullies are hard to identify. However, it is possible to identify that the same overall shape of the site has been maintained. This may be seen more clearly in Figure 2d, where the DEM has been filtered with a $5 \times 5$ Gaussian filter to remove the high-frequency noise, though there are still artifacts on the flatter northern section of the site.

By an error propagation analysis of the EDM tacheometry equations, the original EDM data were found to have centimeter accuracy with significant correlations existing only between errors in easting and northing. From a Monte Carlo analysis of the Delaunay triangulation gridding procedure [Sloan, 1993] the gridded EDM data were found to have slightly larger errors in elevation than the original data, with the majority of grid points having a standard deviation of less than $5 \mathrm{~cm}$. It was also found that errors in elevations and derived slopes for the gridded data could be described by an isotropic single-exponential correlation function, with correlation lengths directly proportional to the raw data spacing. The DEM-derived slopes from finite differences were found to have an average error of $0.5 \%$.

By comparison with EDM data the cartometric DEMs were
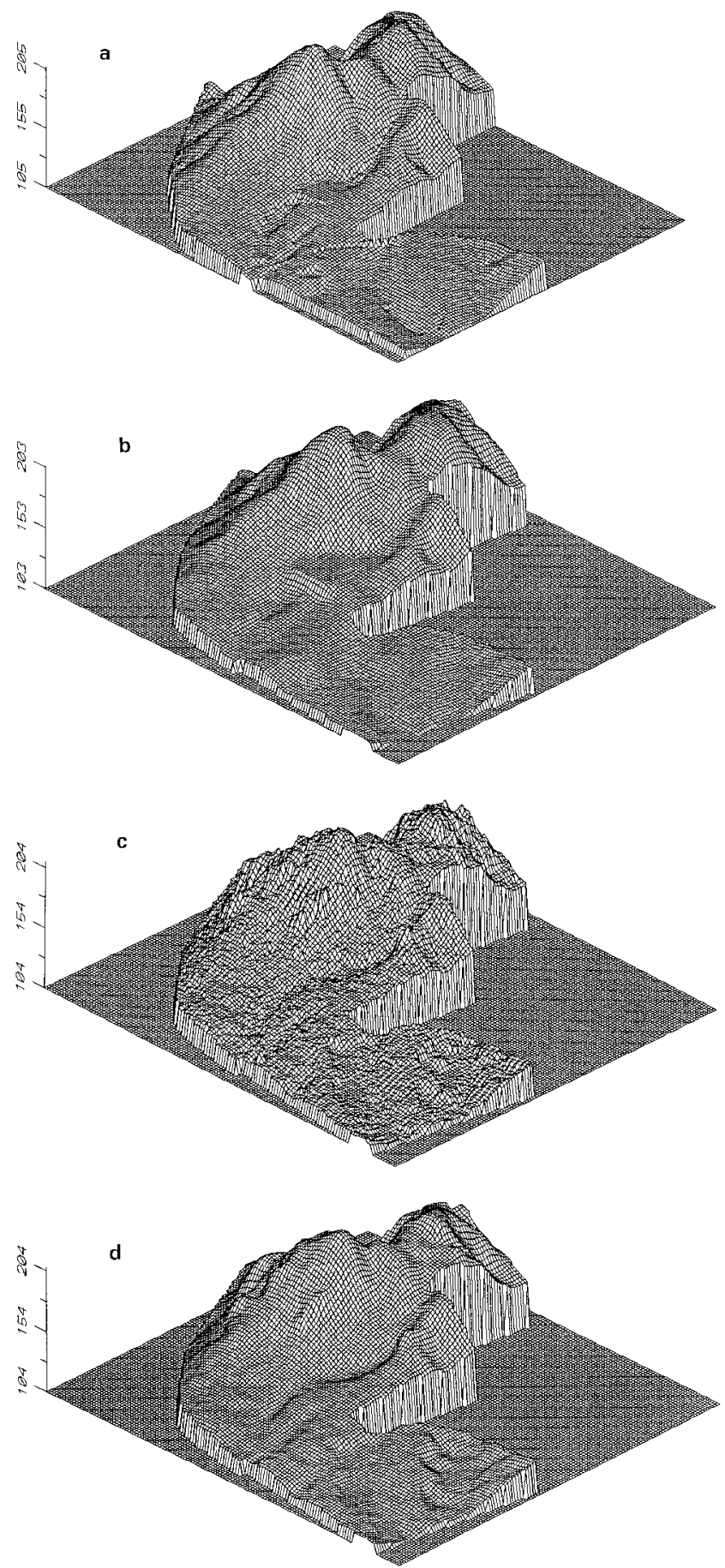

Figure 2. Surface plots of (a) ground truth digital elevation model (DEM), (b) cartometric DEM, (c) photogrammetric DEM, and (d) photogrammetric DEM after filtering with a $5 \times 5$ Gaussian filter. Horizontal plot size is $1400 \mathrm{~m} \times 1800 \mathrm{~m}$; vertical exaggeration is 5 .

found to be more accurate than the photogrammetric DEMs, with rms errors in elevation of approximately $3.5 \mathrm{~m}$ and $4.5 \mathrm{~m}$, respectively, and maximum absolute errors in elevation of approximately $12 \mathrm{~m}$ and $28 \mathrm{~m}$, respectively. Absolute rms errors in DEM-derived slope were approximately $6 \%$ and $20 \%$ for the cartometric and photogrammetric DEMs, respectively, with maximum absolute DEM-derived slope errors of approximately $75 \%$ and $290 \%$, respectively. The cartometric DEMs 


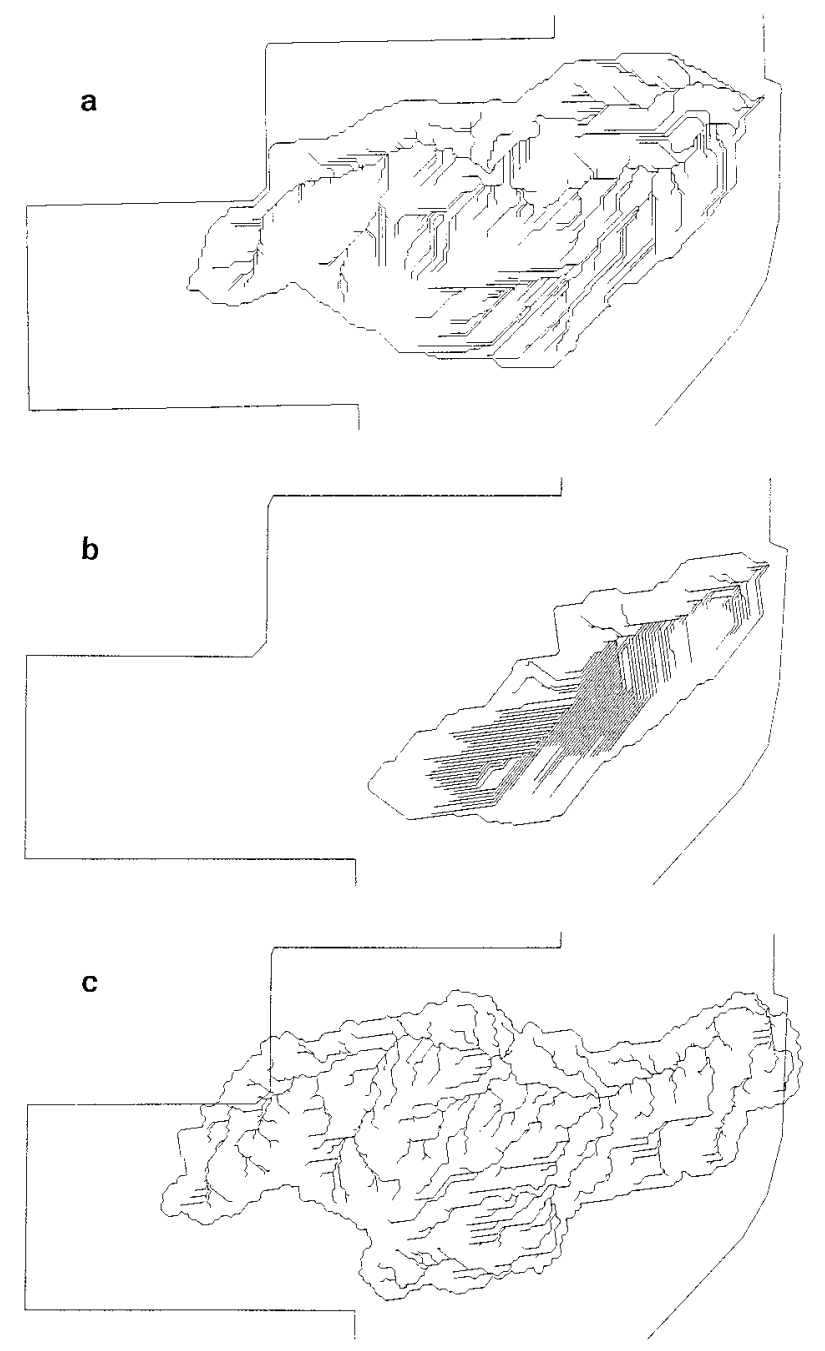

Figure 3. Catchment and stream network from (a) ground truth DEM, (b) cartometric DEM, and (c) photogrammetric DEM for initial outlet position with data on a $6.25 \mathrm{~m}$ grid spacing.

satisfy the U.S. Geological Survey (USGS) specifications for level 2 data, which is currently the highest level of accuracy at which DEMs are produced by the USGS [Moore et al., 1991].

\subsection{Effects of DEM Errors on Hydromorphic Parameters}

In assessing the effects of DEM error on geomorphic parameters, both qualitative and quantitative assessments were undertaken. The qualitative assessment was made by comparing the inferred stream networks, catchment boundary, and study site boundary from each of the published DEMs with that from the ground truth DEM. The threshold area used for defining the stream networks in this qualitative analysis was nominally set to $625 \mathrm{~m}^{2}$. The quantitative assessment of the effects on geomorphic parameters was made by comparing plots of the width function, slope-area relationship, and cumulative area relationship from the published DEMs with $90 \%$ confidence limits derived from the ground truth DEM. The quantitative analysis is independent of the threshold area chosen above, as geomorphic parameters were estimated from all grid cells (flow paths) contained in the catchment inferred from the DEM.
The confidence limits on the ground truth were determined from Monte Carlo simulations, which involved simulating 100 replicate ground truth data sets using error estimates for the tacheometry, assuming each survey observation to be independent. Data sets were simulated by adding a perturbation to the $x, y$, and $z$ coordinates of each original data point, using the covariance matrix of that data point. The covariance matrices were estimated from error theory [Mikhail and Ackerman, 1976] by differentiation of the observation equations [Fryer et al., 1987] and evaluation using the raw observations. Given the large correlation between the $x, y$, and $z$ coordinates of the individual data points, random perturbations to the data points were estimated by sampling from a multivariate normal distribution using a technique which maintained the correlation structure between the perturbations of the $x, y$, and $z$ coordinates. As the published DEMs were provided on a regular grid and the method used for extracting the inferred stream network [O'Callaghan and Mark, 1984] and associated geomorphic parameters was based upon the data being on a regular grid, the 100 simulated data sets were interpolated onto a grid using linear interpolation triangles. The width function, slopearea relationship, and cumulative area relationship were then evaluated for each of the 100 replicate gridded elevation data from which $90 \%$ confidence limits on the geomorphic parameters were estimated by ranking and selecting the 5 th and 95 th values.

The location for the catchment outlet used in this study was taken as the grid point in the original ground truth DEM which drained the largest catchment area. However, the main stream network did not pass through the same outlet position for the 100 replicates of the ground truth but moved either north or south by one or two pixels. Therefore the specified outlet position was the nearest grid point with the same easting. An interesting feature of the adopted catchment outlet was that it was only slightly downstream from a junction of two major streams (Figure 3a), requiring special care to ensure that the correct catchment was identified.

Gyasi-Agyei et al. [1995] suggested that a DEM is adequate for extracting the stream network, if the ratio of average pixel drop and vertical resolution is greater than unity. The average pixel drop can be determined from the average slope and grid spacing, and the vertical resolution can be considered as being approximately equal to the standard deviation of relative errors between grid points.

$$
\frac{\text { average pixel drop }}{\text { vertical resolution }} \approx \frac{\alpha D_{x}}{\sigma_{\Delta z}}>1
$$

where $\alpha$ is the mean slope $(\mathrm{m} / \mathrm{m}), D_{x}$ is the grid point spacing (in meters), and $\sigma_{\Delta z}$ is the standard deviation of relative error in elevation (in meters).

The standard deviation of relative error in elevation can be estimated using two approaches. In the first approach the standard deviation of relative errors can be estimated by an autoregressive order 1 series [Bras and Rodriguez-Iturbe, 1985], using the error analysis of the differences between the published and the ground truth DEMs. The relationship used to describe this is

$$
\sigma_{\Delta z}=\sigma_{z} \sqrt{1-\rho_{1}^{2}}
$$

where $\sigma_{z}$ is standard deviation of absolute error in elevation (in meters) and $\rho_{1}$ is the lag 1 correlation. The lag 1 correlation is the correlation of absolute error in elevation at a distance of 
Table 1. Results From Evaluation of the Empirical Relationship Describing the Adequacy of a DEM for Hydrological Applications

\begin{tabular}{|c|c|c|c|c|c|c|}
\hline & \multicolumn{3}{|c|}{ Cartometric DEM } & \multicolumn{3}{|c|}{ Photogrammetric DEM } \\
\hline & $\begin{array}{l}6.25 \mathrm{~m} \text { Grid } \\
\text { Resolution }\end{array}$ & $\begin{array}{l}12.5 \mathrm{~m} \text { Grid } \\
\text { Resolution }\end{array}$ & $\begin{array}{l}25.0 \mathrm{~m} \text { Grid } \\
\text { Resolution }\end{array}$ & $\begin{array}{l}6.25 \mathrm{~m} \text { Grid } \\
\text { Resolution }\end{array}$ & $\begin{array}{l}12.5 \mathrm{~m} \text { Grid } \\
\text { Resolution }\end{array}$ & $\begin{array}{l}25.0 \mathrm{~m} \text { Grid } \\
\text { Resolution }\end{array}$ \\
\hline Average slope, m/m & 0.081 & 0.112 & 0.122 & 0.138 & 0.171 & 0.085 \\
\hline Average pixel drop, m & 0.51 & 1.40 & 3.05 & 0.86 & 2.14 & 1.10 \\
\hline Correlation length, m & 304 & 286 & 143 & 128 & 80 & 174 \\
\hline Lag 1 correlation & 0.98 & 0.96 & 0.84 & 0.95 & 0.86 & 0.93 \\
\hline Standard deviation of absolute errors in elevation, $\mathrm{m}$ & 2.57 & 2.89 & 2.73 & 4.00 & 2.97 & 2.58 \\
\hline $\begin{array}{l}\text { Standard deviation of relative errors in elevation by } \mathrm{AR}(1) \\
\text { series, } \mathrm{m}\end{array}$ & 0.51 & 0.81 & 1.48 & 1.25 & 1.52 & 0.94 \\
\hline Ratio of average drop to vertical resolution by $\mathrm{AR}(1)$ series & 1.0 & 1.7 & 2.1 & 0.7 & 1.4 & 1.2 \\
\hline Standard deviation of slope errors, $\mathrm{m} / \mathrm{m}$ & 0.062 & 0.054 & 0.053 & 0.188 & 0.123 & 0.063 \\
\hline $\begin{array}{l}\text { Standard deviation of relative errors in elevation by standard } \\
\text { deviation of slope, } \mathrm{m}\end{array}$ & 0.39 & 0.68 & 1.33 & 1.18 & 1.54 & 0.79 \\
\hline Ratio of average drop to vertical resolution by slope & 1.3 & 2.1 & 2.3 & 0.7 & 1.4 & 1.4 \\
\hline
\end{tabular}

one grid spacing away. Using the calculated correlation function and correlation length, the lag 1 correlation was estimated (Table 1).

The second approach uses the standard deviation of errors in slope $(\mathrm{m} / \mathrm{m})$ which have been evaluated for each of the published DEMs. The standard deviation of relative errors in elevation was evaluated by multiplying the standard deviation of slope with the respective grid spacing (Table 1). In this way the empirical relationship for checking DEM adequacy was tested for the DEMs used in this study.

\section{Results and Discussion}

\subsection{Qualitative Assessment of Effects on Geomorphic Parameters}

Plots of inferred stream networks and catchment boundaries for the ground truth, cartometric, and photogrammetric DEMs are given in Figure 3 for $6.25 \mathrm{~m}$ grid spacing. In the ground truth DEM (Figure 3a) a small corner of the catchment under analysis is missed because of a lack of data in the upper reaches. However, this is not considered to have a significant effect on the comparison of results in the quantitative analysis, as the plots of the catchments and stream networks for the published DEMs are significantly different from those obtained for the ground truth.

Although Figure 3 only shows plots of inferred stream networks and catchment boundaries for DEMs with $6.25 \mathrm{~m}$ grid

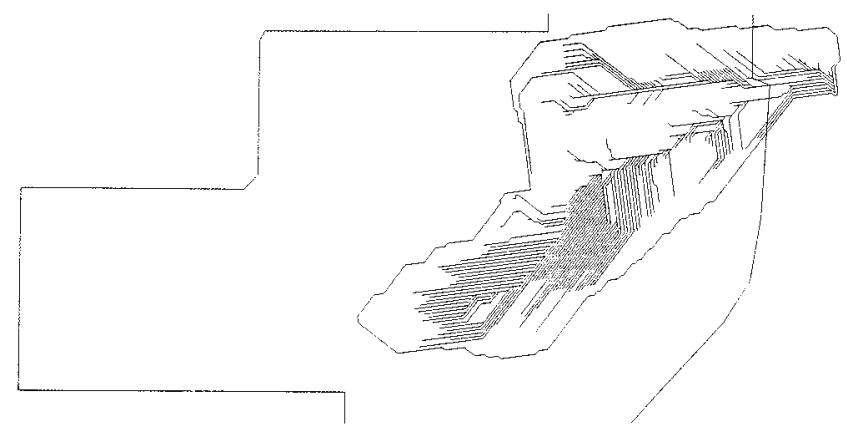

Figure 4. Catchment and stream network from cartometric DEM for outlet chosen farther downstream from where the two stream lines join. spacing, plots of inferred stream networks and catchment boundaries at the coarser-grid spacings were not significantly different apart from a decrease in resolution. This suggests that grid spacings finer than $25 \mathrm{~m}$ do not have a significant effect on the ability to extract the inferred stream network and catchment boundary.

The stream network inferred from the photogrammetric DEM (Figure 3c) appears to be more realistic than that from the ground truth DEM (Figure 3a). This is a result of the parallel streamlines in Figure $3 \mathrm{a}$ on the planar hillslopes and the relatively low threshold area chosen for visual representation of flow paths. The stream network in Figure $3 \mathrm{c}$ does not posses so many parallel flow paths as a result of the highfrequency noise in elevation data seen in Figure 2c.

The catchment area identified from the cartometric DEMs (18 ha) in Figure 3b is significantly different from the ground truth (42 ha) in Figure 3a. These plots reveal that the catchments and stream networks identified from the cartometric DEMs are similar in shape to that for the southern main stream identified in the ground truth, indicating that the two main streams evident in the ground truth had not yet converged at the outlet in the cartometric DEMs. A field inspection of the outlet clearly indicated that the two main gullies converged before the specified outlet, and hence an assessment was made of the cartometric DEMs for an outlet farther downstream.

Figure 4 contains a plot of the inferred catchment and stream network from the cartometric DEM with $6.25 \mathrm{~m}$ grid spacing for an outlet far enough downstream to capture the convergence of the two streams. However, the second major stream was still not captured in its entirety. It is evident from these plots that the second major stream only extends back as far as the large farm dam and that the hypothesis of the cartometric DEMs draining water from the dam into the next gully is correct.

From the plot of catchment boundary and stream network for the photogrammetric DEM (Figure 3c) it may be seen that the catchment area ( $42 \mathrm{ha}$ ) is of a similar size to that of the ground truth (Figure 3a). However, the shape of the catchment and the stream network within it are quite different. The major difference is that the two main streams evident in the ground truth and converging near the outlet cannot be seen in the stream networks identified from the photogrammetric DEMs, 


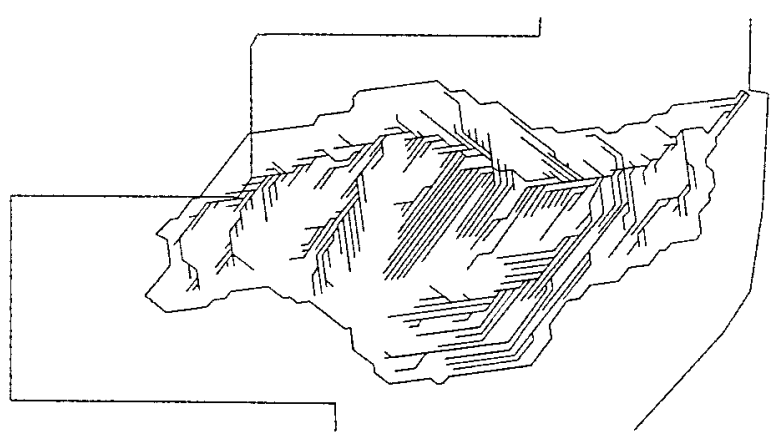

Figure 5. Catchment and stream network from photogrammetric DEM on $12.5 \mathrm{~m}$ grid, filtered with a $5 \times 5$ Gaussian filter, for initial outlet position.

with only one main stream being identified. The reason for this is evident in Figures 2 and 3. In comparing Figures 3a and 3c, the major difference in the stream network begins at the location of the large farm dam. In Figure 3c (photogrammetric DEM) the main northern stream has cut back across to the main southern stream rather than continuing on in the same manner as the ground truth in Figure $3 a$. Figures $2 a$ and $2 d$ show that the dam has interfered with the elevations in the DEM, with the upper section of the catchment draining across to another gully within the catchment. This can be contrasted with the cartometric DEMs which have drained the upper section of the catchment across to a gully outside the identified catchment.

The catchment and inferred stream networks for the photogrammetric DEM on a $12.5 \mathrm{~m}$ grid filtered with a $5 \times 5$ Gaussian filter were also extracted for the initial outlet position and are presented in Figure 5. The catchment and inferred stream network for the filtered data are similar to that for the original data (Figure 3c), with the exception of the streamlines becoming parallel. As the size of the filter increased, it was observed that more parallel streamlines were formed as the surface became smoother. These parallel streamlines are also a feature of the stream networks from the cartometric DEMs.

The main reason for the differences in stream networks from the ground truth in Figure 3 is the near coincidence of the confluence of the two main streams and the selected outlet position. To investigate how close the inferred stream network and catchment boundary might be to the ground truth in the absence of this coincidence, an outlet upstream of where the two main streams merge was selected. Figure 6 shows the plots of inferred catchment and stream network from the published and ground truth DEMs with $6.25 \mathrm{~m}$ grid spacing. Plots from coarser-grid spacings were similar.

The catchment area identified from the cartometric DEMs (18 ha) in Figure 6b is approximately the same as that for the ground truth (17 ha) in Figure 6a. Inferred catchment and stream network shapes for the cartometric DEMs are essentially the same as the ground truth apart from more parallel streamlines. However, Figure $6 \mathrm{c}$ shows that the inferred catchment area from the photogrammetric DEMs (39 ha) is significantly different from the ground truth $(17 \mathrm{ha})$. The reason for the inferred catchment area from the photogrammetric DEMs being so large is that only one main stream was identified, resulting in little loss of catchment area from the initial outlet position.

This qualitative assessment of inferred stream networks and catchments from published DEMs shows that the stream network and catchment boundary can be significantly in error. However, a DEM grid spacing of less than $25 \mathrm{~m}$ does not appear to have a significant effect on the adequacy of the DEM to identify the catchment and stream network. This suggests that the underlying data source used for deriving the DEMs is the crucial factor in the observed differences.

\subsection{Quantitative Assessment of Effects on Geomorphic Parameters}

The comparisons of geomorphic parameters presented here are only for those locations of catchment outlet which gave the best qualitative catchment representation, that is, (1) the upstream outlet position for the cartometric DEM (Figure 6b) and (2) downstream outlet position for the photogrammetric DEM (Figure 3c).

These plots are for a $6.25 \mathrm{~m}$ grid spacing; the other grid spacings gave similar results. The exception to this indepen-
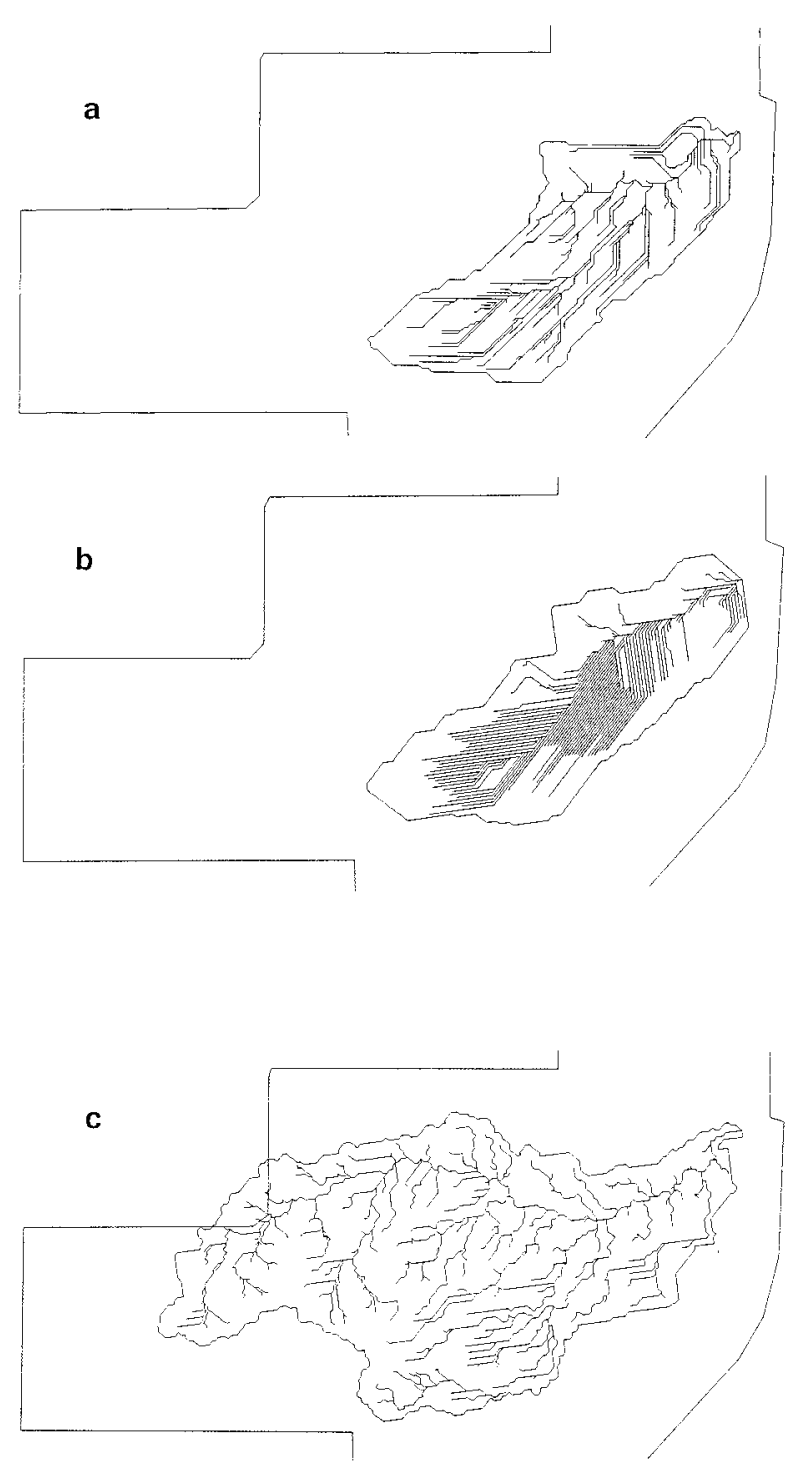

Figure 6. Catchment and stream network from (a) ground truth DEM, (b) cartometric DEM, and (c) photogrammetric DEM for outlet upstream from where the two stream lines join with data on a $6.25 \mathrm{~m}$ grid. 
dence of grid spacing was the cumulative area relationship which was scale dependent, as previously identified by La Barbara and Roth [1994]. Thus the only cumulative area diagrams which could be directly compared with the $90 \%$ confidence limits (derived for a $6.25 \mathrm{~m}$ grid spacing) were those from the published DEMs on a $6.25 \mathrm{~m}$ grid. Cumulative area diagrams at larger grid spacings maintained the same overall shape, except that they moved to the right with increasing grid spacing.

The width functions for the cartometric and photogrammetric DEMs are given in Figure 7 . Though the $90 \%$ confidence limits are quite wide, neither of the width functions from the published DEMs are contained within these limits. The wide confidence limits on the width function indicate that the width function is very sensitive to even small errors in the elevations. Although it would be expected that the width function would be outside the $90 \%$ confidence limits for $10 \%$ of the relationship on average, the width function for the cartometric and photogrammetric DEMs is outside the limits for $60 \%$ and $70 \%$, respectively. For the photogrammetric DEM this is because the inferred stream network is significantly different from that of the ground truth. However, the inferred stream network for the cartometric DEM is very similar to that of the ground truth, yet it has not given any better results. An explanation for this may be the parallel streamlines which can be clearly seen in Figure 6b.

The slope-area relationship was estimated reasonably well for both the cartometric and photogrammetric DEMs (Figure 8 ), lying outside the limits for $30 \%$ and $40 \%$ of the relationship, respectively. Although not presented here, slope-area

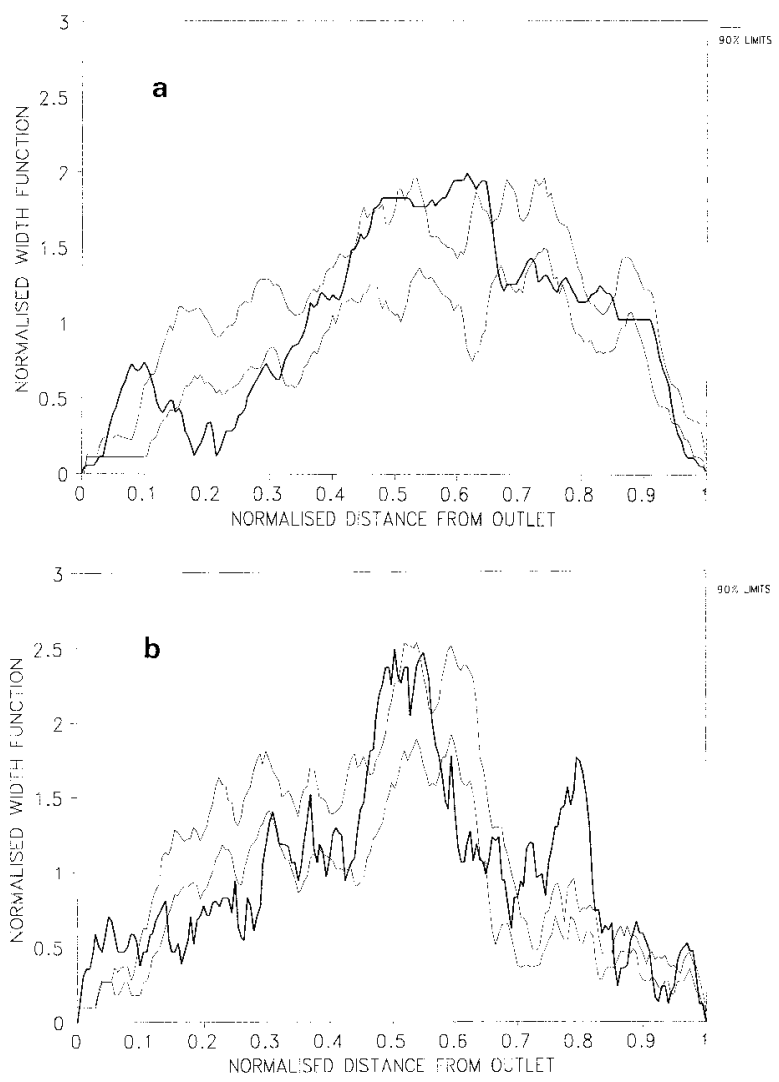

Figure 7. Width function from data on $6.25 \mathrm{~m}$ grid spacing for (a) cartometric DEM with the upstream outlet position and (b) photogrammetric DEM with the original outlet position.
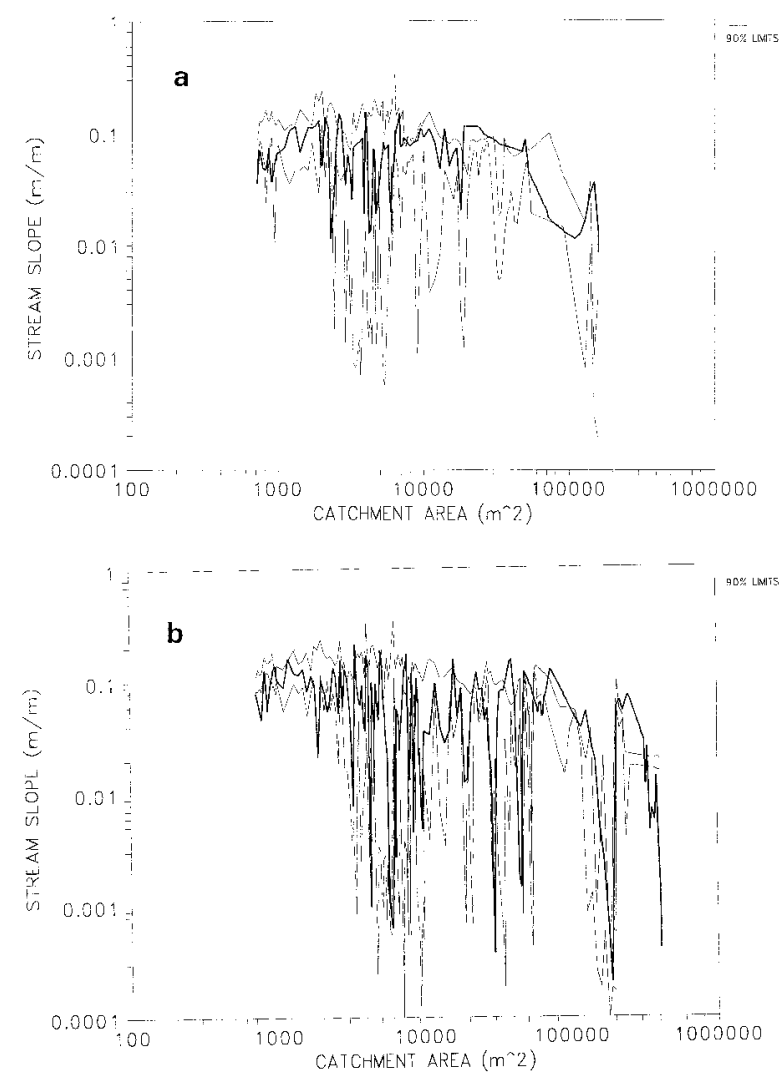

Figure 8. Slope-area relationship from data on $6.25 \mathrm{~m}$ grid spacing for (a) cartometric DEM with the upstream outlet position and (b) photogrammetric DEM with the original outlet position.

relationships for the other catchment outlet locations gave qualitatively similar results. Hence the slope-area relationship appears to be less sensitive to the accuracy of the DEM, as the identified catchments were significantly different from that of the ground truth in some instances. The increased number of spikes for the photogrammetric DEM is due to the highfrequency noise in the elevations and would be less intense if the elevations were filtered, but the slope scatter is clearly sensitive to elevation errors.

The cumulative area relationships are given in Figure 9, showing that the $90 \%$ confidence limits are very tight, and the cumulative area relationships determined for the published DEMs are far from lying within these limits. The cumulative area relationship which fits the limits best is that from the photogrammetric DEM; however, neither of the fits are satisfactory. This is counterintuitive, given that the cartometric DEM has produced a closer representation of the catchment and stream network than that from the photogrammetric DEM. An explanation for this may again be the parallel streamlines inferred from the cartometric DEMs. The narrow confidence limits which can be seen on the cumulative area diagram suggest that it is relatively insensitive to small elevation errors.

These geomorphic relationships were investigated for all outlet locations and gave qualitatively worse results than those presented here, the exception being the slope-area relationship which was independent of the catchment outlet location or the 


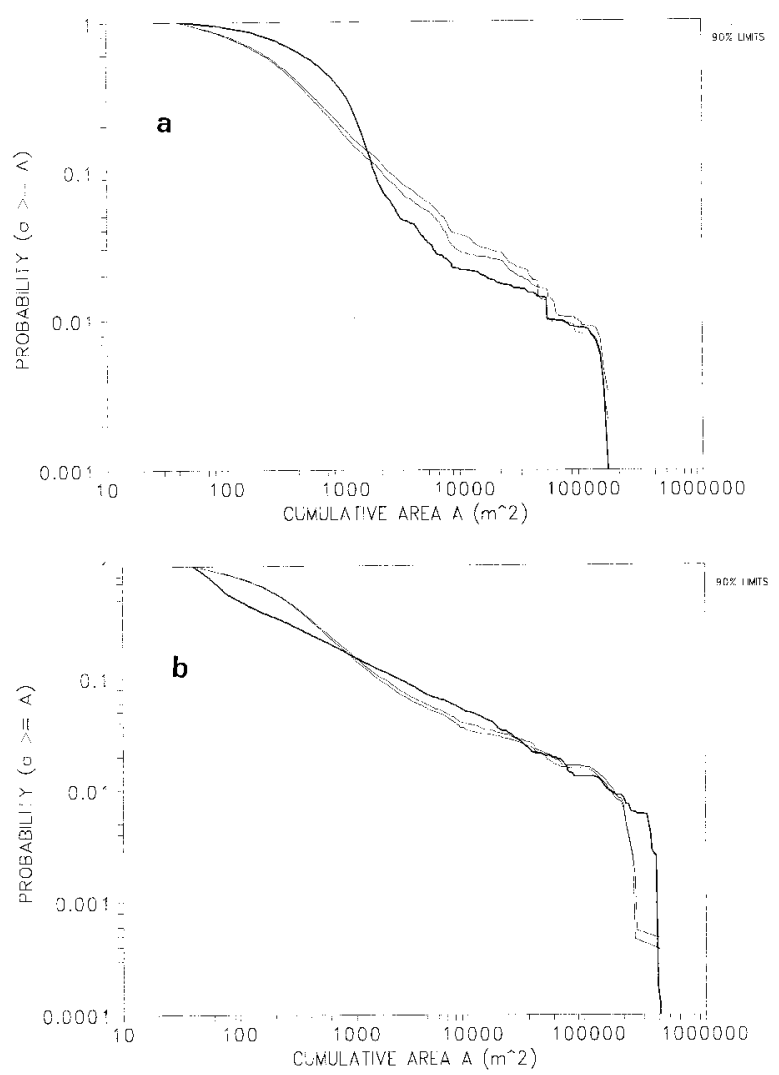

Figure 9. Cumulative area relationship from data on $6.25 \mathrm{~m}$ grid spacing for (a) cartometric DEM with the upstream outlet position and (b) photogrammetric DEM with the original outlet position.

identified catchment boundary and stream network, indicating its independence of catchment shape and stream network.

This quantitative analysis shows that published DEMs can be used to determine the slope-area relationship with greater reliability than the width function and cumulative area relationship, which cannot be determined with high confidence. Since the width function characterizes the catchment routing behavior (through the unit hydrograph), this study suggests that the catchment routing behavior would be poorly estimated from published DEMs. Furthermore, the poor fit for the cumulative area diagrams suggests that the region of saturation predicted for the saturation excess runoff generation mechanism would be poorly estimated from the published DEMs [Hemantha and Willgoose, 1996].

\subsection{Evaluation of DEM Accuracy for Hydrologic Purposes by Empirical Relationship}

Table 1 lists the data required for evaluating the empirical relationship of Gyasi-Agyei et al. [1995] along with the results and estimates of the standard deviation of relative errors in elevation.

The average slope for the study site increased as the grid spacing increased for both the cartometric and photogrammetric DEMs. However, the standard deviation of errors in slope decreased as the grid spacing increased for both DEM types. This decrease in standard deviation of slope is to be expected for the photogrammetric DEM given the amount of highfrequency noise but is more difficult to explain for the cartometric DEM given the smoothness of the surface. However, the trend is weak for the cartometric DEMs, and this may indicate that the trend is coincidental, with differences being sample effects.

The correlation length of errors in elevation decreased with increasing grid spacing for both the cartometric and photogrammetric DEMs. Furthermore, the shorter correlation length of errors in elevation for the photogrammetric DEMs relative to the cartometric DEMs is consistent with the large standard deviations in DEM-derived slope for the photogrammetric DEM (19\%) in comparison to the cartometric DEM $(6 \%)$ and the relatively noisy surface. Filtering of the photogrammetric DEM on a $12.5 \mathrm{~m}$ grid spacing with a $5 \times 5$ Gaussian filter reduced the standard deviation of slope error to the same order as that for the cartometric DEM, with a corresponding increase in correlation length. The lag 1 correlation decreases with increasing grid spacing for both the cartometric and photogrammetric DEMs as expected.

The average DEM-derived slope for the unfiltered photogrammetric DEMs is greater than that for the cartometric DEMs at corresponding grid spacings. This is expected, given the large amount of high-frequency noise observed in the photogrammetric DEMs. Filtering of the photogrammetric DEM with a $5 \times 5$ Gaussian filter reduced the average slope to less than that for the cartometric DEM at a corresponding grid spacing. This would suggest that more smoothing has been performed to the photogrammetric DEM than to the cartometric DEM.

The standard deviation of absolute errors in elevation show no consistent trends with grid spacing, and the standard deviations of absolute errors in elevation for the photogrammetric DEMs are significantly greater than those for the cartometric DEMs, as expected. Filtering of the photogrammetric DEM with the $5 \times 5$ Gaussian filter reduced the standard deviation of absolute errors in elevation to the same level as for the cartometric DEMs.

The standard deviation of relative errors in elevation, however, shows a consistent trend with grid spacing for both the cartometric and photogrammetric DEMs, with standard deviation increasing for increased grid spacing using both approaches. This increase in standard deviation with grid spacing is to be expected as the correlation between errors in elevation of adjacent grid points decreases with increased separation. The coefficient of variation of slope estimates decreases with decreasing resolutions as the slopes are better estimated by lower resolution DEMs for both DEM types.

The results from an evaluation of the empirical relationship presented by Gyasi-Agyei et al. [1995] gave similar results for both approaches and show that the ratio of average pixel drop to vertical resolution is greater than or equal to unity in all but one case, that is, the photogrammetric DEM on a $6.25 \mathrm{~m}$ grid. Thus this relationship would indicate that the cartometric DEMs and photogrammetric DEM on a $12.5 \mathrm{~m}$ grid could be used to extract the catchment and drainage network adequately. However, the plots of catchment and stream network in Figures 3 to 6 would indicate otherwise, suggesting that the empirical relationship of Gyasi-Agyei et al. [1995] was either too loose or not a sufficient condition for adequacy but was only a necessary condition.

The empirical relationship of Gyasi-Agyei et al. [1995] in (1) can be rearranged to identify the optimal horizontal resolution $D_{x}$ of a DEM as 


$$
D_{x}>\frac{\sigma_{\Delta z}}{\alpha}
$$

If the horizontal resolution is higher (i.e., $D_{x}$ is smaller) than the right-hand side, then the drainage network cannot be reliably extracted. A horizontal resolution equal to the righthand side is therefore the finest DEM resolution from which the drainage network can be extracted. If a high-resolution DEM is used to analyze drainage, only those characteristics of the network with a horizontal length scale greater than $D_{x}$ are reliable, any finer detail is an artifact of the noise in the DEM. $D_{x}^{2}$ might also be used to determine the threshold area for extraction of the drainage network.

It is one thing to be able to extract a drainage network from a DEM; it is another thing entirely for this network to reflect the underlying physics rather than DEM noise. For our cartometric and photogrammetric DEMs the critical resolutions were 5 to $10 \mathrm{~m}$ and $10 \mathrm{~m}$, respectively. These values should be viewed with some caution since Gyasi-Agyei et al. [1995] only determined the threshold in (1) to within a factor of 10 . Furthermore, the resolution is likely to vary across the catchment with varying slope.

\section{Conclusions}

We have shown that the catchment sizes and stream networks determined by published DEMs may be significantly different from the ground truth. This is especially the case if looking at a small catchment, where there is a localized error in the elevation directing a major streamline in a wrong direction. An example of where this occurred in the investigated study site is near the large farm dam. However, it has been shown that the published DEMs should be adequate to describe the catchment and stream network, providing there are no localized effects on elevations. It was also found that the grid spacing of the DEM had no significant effect on the ability of the DEM to identify the catchment and the overall stream network, with only the finer detail changing, provided the same base data is used for gridding. Therefore this study indicates that published cartometric and photogrammetric DEMs may be used for determination of catchments and stream networks with caution by comparing the catchment and major stream network defined from the DEMs with that observed from a site inspection.

The maximum horizontal resolution for which the details of the drainage network are reliable is related to both the vertical accuracy of the DEM and the slope. In order to predict this maximum horizontal resolution for a DEM, it is necessary to estimate the vertical accuracy. If the vertical accuracy is consistent throughout the DEM, independent of elevation and slope, then the horizontal resolution will be governed by the topography in the flattest regions of the catchment.

We have shown that both the width function and cumulative area relationship were very sensitive to elevation errors and to the source of the elevation data. The width function had relatively wide confidence limits. Moreover, even though one of the catchments identified from the cartometric DEMs was very similar to that of the ground truth, it still lay outside the $90 \%$ confidence limits for more than $60 \%$ of the relationships. This suggests that these hydrologic properties will be poorly estimated from published DEMs. For the cartometric DEMs this may have been a result of the extensive parallel streamlines on hillslopes.
Since the width function characterizes the catchment routing behavior, given by the unit hydrograph, this investigation suggests that the catchment routing behavior would be poorly estimated from published DEMs. Furthermore, the poor fit for the cumulative area diagrams suggests that the region of saturation predicted for the saturation excess runoff generation mechanism will also be poorly estimated from the published DEMs.

In contrast, the slope-area relationship was found to be less sensitive to both catchment shape and size, as well as stream network, with all DEMs and catchments providing a relationship which fell outside the $90 \%$ confidence limits for less than $40 \%$ of the relationship. This suggests that the slope-area relationship can be estimated from existing DEM sources more reliably than other geomorphic relationships.

It is believed that these results are indicative of the errors which are likely to exist when extracting hydrogeomorphic parameters from published DEMs around the world, since many are derived by interpolating from 1:25,000 (or there about) scale topographical maps using the blue lines for drainage enforcement [Florinsky, 1998]. The conclusions with regard to photogrammetric DEMs may be considered indicative of the loss of accuracy that might be obtained, but they are by no means definitive, as digital photogrammetry software is rapidly improving. However, the characteristic noisy surface with short correlation length, leading to low slope accuracy and very irregular networks, appears in our experience to be a problem for all existing digital photogrammetry packages, and in all cases some form of filtering is required to remove this noise. At this stage we cannot say definitively what the effect of the noise and filtering might be on hydrologic characteristics.

Visually, the cartometric DEMs investigated were as smooth as the DEM from the ground survey data, with some loss of fine detail, while the unfiltered photogrammetric DEMs presented a rough surface. Therefore photogrammetric DEMs require some sort of filtering and editing before use. The use of $5 \times 5$ Gaussian filter was shown to improve the visual appearance of the surface; however, research into a large number of DEMs for different terrains and different grid sizes with various filters is required before any recommendation may be made about postprocessing requirements.

In order to make concrete conclusions regarding the applicability of results to DEMs around the world, it would be necessary for case studies of this type to be made in diverse locations. This work sets out a framework for such an analysis and justifies the need for both high-precision ground truth data sets and further comparisons by highlighting the potential problems with published DEMs generated using current methods.

Acknowledgments. The provision of ground survey data by Ian Marshall and Associates, Registered Surveyors and Subdivisional Planners, Cessnock, and published DEMs by the Land Information Centre, Bathurst, are gratefully acknowledged. Comments made by George Kuczera are also gratefully acknowledged.

\section{References}

Beven, K. J., and M. J. Kirkby, A physically based, variable contributing area model of basin hydrology, Hydrol. Sci. Bull., 24, 43-69, 1979.

Bolstad, P. V., and T. Stowe, An evaluation of DEM accuracy: Elevation, slope, and aspect, Photogramm. Eng. Remote Sens., 60(11), 1327-1332, 1994.

Bras, R. L., and I. Rodriguez-Iturbe, Random Functions and Hydrology, 559 pp., Addison-Wesley, Reading, Mass., 1985. 
Felicísimo, A. M., Parametric statistical method for error detection in digital elevation models, J. Photogramm. Remote Sens., 49(4), 29-33, 1994.

Florinski, I. V., Combined analysis of digital terrain models and remotely sensed data in landscape investigations, Prog. Phys. Geogr., 22(1), 33-60, 1998.

Fryer, J. G., M. H. Elfick, R. C. Brinker, and P. R. Wolf, Elementary Surveying, 7th ed. (SI adaption), 472 pp., HarperCollins, New York, 1987.

Fryer, J. G., J. H. Chandler, and M. A. R. Cooper, Short communication on the accuracy of heighting from aerial photographs and maps: Implications to process modellers, Earth Surf. Processes Landforms, 19, 577-583, 1994.

Gyasi-Agyei, Y., G. Willgoose, and F. P. De Troch, Effects of vertical resolution and map scale of digital elevation models on geomorphological parameters used in hydrology, Hydrol. Processes, 9, 363-382, 1995.

Hemantha, J., and G. Willgoose, Scaling and scale-invariant behaviour in a geomorphically based conceptual model for runoff generation, Eos Trans. AGU, 77(46), F233, 1996.

Hutchinson, M. F., A new procedure for gridding elevation and stream line data with automatic removal of spurous pits, J. Hydrol., 106, 211-232, 1989.

La Barbara, P., and G. Roth, Invariance and scaling properties in the distribution of contributing area and energy in drainage basins, Hydrol. Processes, 8, 125-135, 1994.

Lane, S. N., J. H. Chandler, and K. S. Richards, Developments in monitoring and modelling small-scale river bed topography, Earth Surf. Processes Landforms, 19, 349-368, 1994.

Mikhail, E. M., and F. Ackerman, Observations and Least Squares, IEP, New York, 497 pp., 1976.

Moore, I. D., and R. B. Grayson, Terrain-based catchment partitioning and runoff prediction using vector elevation data, Water Resour. Res., 27(6), 1177-1191, 1991.
Moore, I. D., R. B. Grayson, and A. R. Ladson, Digital terrain modelling: A review of hydrological, geomorphological and biological applications, Hydrol. Processes, 5, 3-30, 1991.

O'Callaghan, J. F., and D. M. Mark, The extraction of drainage networks from digital elevation data, Comput. Vision, Graphics, Image Process., 28, 323-344, 1983.

Robinson, G. J., The accuracy of digital elevation models derived from digitised contour data, Photogramm. Rec., 14(83), 805-814, 1994.

Sloan, S. W., A fast algorithm for generating constrained delaunay triangulations, Comput. Struct., 47(3), 441-450, 1993.

Surkan, A. J., Synthetic hydrographs: Effects of network geometry, Water Resour. Res., 5(1), 112-128, 1969.

Tarboton, D. G., R. L. Bras, and I. Rodriguez-Iturbe, The analysis of river basins and channel networks using digital terrain data, Tech. Rep. 326, Ralph M. Parsons Lab., Dep. of Civ. Eng., Mass. Inst. of Technol., Cambridge, 1989.

Willgoose, G., R. L. Bras, and I. Rodriguez-Iturbe, A physical explanation of an observed link area-slope relationship, Water Resour. Research, 27(7), 1697-1702, 1991.

Wolock, D. M., and C. V. Price, Effect of digital elevation model map scale and data resolution on a topography-based watershed model, Water Resour. Res., 30(11), 3041-3052, 1994

Zhang, W., and D. Montgomery, Digital elevation model grid size, landscape representation, and hydrologic simulations, Water Resour. Research, 30(4), 1019-1028, 1994.

J.P. Walker and G.R. Willgoose, Department of Civil, Surveying and Environmental Engineering, University of Newcastle, Callaghan, NSW 2308,Australia.(cejpw@cc.newcastle.edu.au.; cegrw@cc.newcastle. edu.au.)

(Received August 7, 1998; revised January 29, 1999; accepted February 1, 1999.) 